\title{
A NOTE ON COMPLEMENTARITY PROBLEM IN BANACH SPACE
}

\author{
S. NANDA AND S. PANI
}

Abstract. The purpose of this note is to establish an existence theorem for nonlinear complementarity problem for strictly pseudo-monotone operator over convex cone in a Banach space.

Mathematics subject classification (2000): 90C30; 49N15.

Key words and phrases: Variational inequalities, complementarity problems, closed convex cone, strictly pseudo-monotone operator.

\section{REFERENCES}

[1] F. E. Browder, Nonlinear Monotone Operators and Convex Sets in Banach Spaces, Bull. Amer. Math. Soc. 71 (1965), 780-785.

[2] P. Hartman and G. Stampacchia, On some Nonlinear Elliptic Differential Functional Equations, Acta Math. 115 (1996), 271-310.

[3] S. Karamardian, Generalized Complementarity Problem, Journal of Optimization Theory and Applications 8 (1971), 161-168.

[4] J. L. Lions and G. Stampacchia, Variational Inequalities, Comm. Pure Appl. Math. 20 (1967), 493-519.

[5] U. Mosco, Convergence of Convex Sets and Solutions of Variational Inequalities, Adv. Math. 3 (1966), $510-585$

[6] S. NANDA, On a Complementarity Problem in Banach Space, Proceedings of the American Mathematical Society, 4 (1994), 1203-1205.

[7] S. NANDA, Nonlinear Complementarity Problem of Mathematical Programming in Banach Space, Indian Journal of Pure and Applied Mathematics, 18 (3) (1987), 215-218.

[8] M. THERA, Existence Results for the Nonlinear Complemantarity Problem and Application to Nonlinear Analysis, J. Math. Anal. Appl. 154 (1991), 572-584.

[9] Jen-ChIn YAO, Variational Inequality, Appl. Math. Lett. Vol 5, No 1 (1992), 39-42. 